\title{
A ONE-PARAMETER FAMILY OF BIVARIATE MEANS
}

\author{
EDWARD NEUMAN
}

Abstract. A one-parameter family of bivariate means is introduced. Members of the new family of means are derived from a bivariate symmetric mean. It is shown that new means are symmetric in their variables. Several inequalities involving parametric versions of two Seiffert means, the Neuman-Sándor mean, and the logarithmic means are obtained. It is shown that the last four means belong to the family of the Schwab-Borchardt means. Among inequalities established in this paper some provide generalizations of known results obtained recently by several researchers.

Mathematics subject classification (2010): Primary: 26E60; Secondary: 26D07, 26 D20.

Keywords and phrases: Bivariate means, Seiffert means, Neuman-Sándor mean, logarithmic mean, Schwab-Borchardt mean, inequalities, convex combinations.

\section{REFERENCES}

[1] J. M. Borwein, P. B. Borwein, Pi and AGM: A Study in Analytic Number Theory and Computational Complexity, John Wiley and Sons, New York, 1987.

[2] B. C. CARlson, Algorithms involving arithmetic and geometric means, Amer. Math. Monthly 78 (1971), 496-505.

[3] Y.-M. CHU, S.-W. Hou, Sharp bounds for Seiffert mean in terms of contra-harmonic mean, Abstr. Appl. Anal. 2012 (2012), Article ID 425175.

[4] Y.-M. CHU, S.-W. Hou, Z.-H. SHEN, Sharp bounds for Seiffert mean in terms of root mean square, J. Inequal. Appl. 2012, 11 (2012), 15 pages.

[5] Y.-M. CHU, Y.-F. QIU, M.-K. WANG, G.-D. WANG, The optimal convex combination bounds of arithmetic and harmonic means for the Seiffert mean, J. Inequal. Appl. 2010 (2010), Article ID 436457.

[6] Y.-M. Chu, M.-K. WAng, W.-M. Gong, Two sharp double inequalities for Seiffert mean, J. Inequal. Appl. 2011, 44 (2011), 7 pages.

[7] Y.-M. CHU, M.-K. WANG, S.-L. QIU, Y.-F. QIU, Sharp generalized Seiffert mean bounds for Toader mean, Abstract Appl. Anal., Volume 2011, Article ID 605259.

[8] Y.-M. Chu, M.-K. Wang, Z.-K. WAng, A best possible double inequality between Seiffert and harmonic means, J. Inequal. Appl. 2011, 44 (2011), 7 pages.

[9] Y.-M. Chu, C. Zong, G.-D. WANG, Optimal convex combination bounds of Seiffert and geometric means for the arithmetic mean, J. Math. Inequal. 5 (2011), 429-434.

[10] S.-Q. GAO, H.-Y. GAO, W.-Y. SHI, Optimal convex combination bounds of the centroidal and harmonic means for the Seiffert mean, Int. J. Pure Appl. Math. 70 (2011), 701-709.

[11] Y.-M. Li, B.-Y. LonG, Y.-M. CHU, Sharp bounds for the Neuman-Sándor mean in terms of generalized logarithmic mean, J. Math. Inequal. 4, 4 (2012), 567-577.

[12] H. LiU, X.-J. Meng, The optimal convex combination bounds for Seiffert's mean, J. Inequal. Appl. 2011 (2011), Article ID 686834.

[13] D. S. MitrinovĆ, Analytic Inequalities, Springer-Verlag, Berlin, 1970.

[14] E. Neuman, Inequalities for the Schwab - Borchardt mean and their applications, J. Math. Inequal. 5, 4 (2011), 601-609.

[15] E. Neuman, A note on a certain bivariate mean, J. Math. Inequal. 6, 4 (2012), 637-643.

[16] E. NEUMAN, Inequalities for weighted sums of powers and their applications, Math. Inequal. Appl. 15, 4 (2012), 995-1005. 
[17] E. NeUman, Refinements and generalizations of certain inequalities involving trigonometric and hyperbolic functions, Adv. Inequal. Appl. 1, 1 (2012), 1-11.

[18] E. Neuman, J. SÁndor, On the Schwab - Borchardt mean, Math. Pannon. 14, 2 (2003), 253-266.

[19] E. Neuman, J. SÁndor, On the Schwab-Borchardt mean II, Math. Pannon. 17, 1 (2006), 49-59.

[20] H.-J. SeIfFerT, Problem 887, Nieuw. Arch. Wisk. 11 (1993), 176.

[21] H.-J. SEIFFERT, Aufgabe 16, Würzel 29 (1995), 87.

[22] G. TOADER, Seiffert type means, Nieuw. Arch. Wisk. 17, 3 (1999), 379-382.

[23] A. WitKows KI, Interpolations of Schwab-Borchardt means, Math. Inequal. Appl., in press.

[24] M.-K. WANG, Y.-M. ChU, B.-Y. LiU, Sharp inequalities for the Neuman-Sándor mean in terms of arithmetic and contra-harmonic means, preperint, arXiv: 1209.5825 vol 1 [math CA] 26 Sep. 2012. 